\title{
Decreased Circulating T Regulatory Cells in Egyptian Patients with Nonsegmental Vitiligo: Correlation with Disease Activity
}

\author{
Doaa Salah Hegab ${ }^{1}$ and Mohamed Attia Saad Attia ${ }^{2}$ \\ ${ }^{1}$ Faculty of Medicine, Dermatology and Venereology Department, Tanta University Hospitals, El Geish Street, Tanta 31111, Egypt \\ ${ }^{2}$ Faculty of Medicine, Clinical Pathology Department, Tanta University Hospitals, El Geish Street, Tanta 31111, Egypt \\ Correspondence should be addressed to Doaa Salah Hegab; doaasalahhegab@yahoo.com
}

Received 10 September 2015; Revised 28 November 2015; Accepted 30 November 2015

Academic Editor: Elizabeth Helen Kemp

Copyright (c) 2015 D. S. Hegab and M. A. S. Attia. This is an open access article distributed under the Creative Commons Attribution License, which permits unrestricted use, distribution, and reproduction in any medium, provided the original work is properly cited.

\begin{abstract}
Background. Vitiligo is an acquired depigmentary skin disorder resulting from autoimmune destruction of melanocytes. Regulatory T cells (Tregs), specifically CD $4^{+} \mathrm{CD} 25^{+}$and Forkhead box $\mathrm{P}^{+}\left(\mathrm{FoxP}^{+}\right)$Tregs, acquired notable attention because of their role in a variety of autoimmune pathologies. Dysregulation of Tregs may be one of the factors that can break tolerance to melanocyte self-antigens and contribute to vitiligo pathogenesis. Methods. In order to sustain the role of Tregs in pathogenesis and disease activity of vitiligo, surface markers for $\mathrm{CD}^{+} \mathrm{CD} 25^{+}$and $\mathrm{FoxP}^{+}$peripheral Tregs were evaluated by flow cytometry in 80 Egyptian patients with nonsegmental vitiligo in addition to 60 healthy control subjects and correlated with clinical findings. Results. Vitiligo patients had significantly decreased numbers of both peripheral $\mathrm{CD} 4{ }^{+} \mathrm{CD} 25^{+}$and $\mathrm{FoxP}^{+} \mathrm{T}$ cells compared to control subjects $\left(11.49 \% \pm 8.58 \%\right.$ of $\mathrm{CD}^{+} \mathrm{T}$ cells versus $21.20 \% \pm 3.08 \%$, and $1.09 \% \pm 0.96 \%$ versus $1.44 \% \pm 0.24 \%$, resp., $P<0.05$ for both). Peripheral numbers of $\mathrm{CD}^{+} \mathrm{CD}_{2} 5^{+}$and FoxP3 ${ }^{+}$Tregs correlated negatively with VIDA score. Conclusion. Treg depletion with impaired immune downregulatory function might play a key role in the autoimmune conditions beyond nonsegmental vitiligo particularly in active cases. Effective Treg cell-based immunotherapies might be a future hope for patients with progressive vitiligo.
\end{abstract}

\section{Introduction}

Vitiligo is an acquired cutaneous disorder characterized by progressive, selective destruction of melanocytes and clinically characterized by the development of milky white macules and patches [1]. It is a multifactorial polygenic disorder and several theories have been proposed about the pathogenesis of vitiligo including autoimmune hypothesis, reactive oxygen species model, zinc- $\alpha 2$-glycoprotein deficiency hypothesis, viral theory, intrinsic theory, and biochemical, molecular, and cellular alterations accounting for loss of functioning melanocytes [2]. The integration of epidemiological, clinical, histoimmunological, and therapeutic data strongly supports immunological pathomechanism in vitiligo, which is commonly associated with autoimmune diseases like autoimmune thyroid diseases, insulin-dependent diabetes mellitus, alopecia areata, and pernicious anemia [3-5].

T regulatory cells (Tregs) are a component of the immune system that constitutes a key mechanism in maintaining peripheral self-tolerance through the control of autoreactive lymphocyte activation and the prevention of harmful effects of such activation. These cells are involved in shutting down immune responses after they have successfully eliminated invading organisms [6]. Natural Tregs express the transcriptional factor Forkhead box P3 (FoxP3), which serves as the dedicated mediator of the genetic program for Tregs development and function. FoxP3 ${ }^{+}$is a reliable and specific marker of Tregs [7]. Natural and induced Tregs have many subsets with the most well-understood being those that express CD4, CD25, and FoxP3 (CD $4^{+} \mathrm{CD} 25^{+}$FoxP $3^{+}$Tregs), which had acquired notable attention because of their role in a variety of autoimmune pathologies, inflammatory disorders such as asthma and colitis, and immune responses to tissue transplants, tumors, and various infectious agents pathologies [8]. There are several other subpopulations of Tregs such as Treg17 cells [9]; interleukin 10- (IL-10-) producing "Trl" cells; transforming growth factor- $\beta$ - (TGF- $\beta$-) producing T 
TABLE 1: Demographic and clinical characteristics of study participants.

\begin{tabular}{lcc}
\hline & Vitiligo patients & $n=60$ \\
& $n=80$ & $20-50,33.9(9.5)$ \\
Range of age in years, mean (SD) & $9-60,27.25(14.32)$ & $36(60)$ \\
Gender, $n(\%)$ & $36(45)$ & $24(40)$ \\
Male & $44(55)$ & NA \\
Female & $0.33-49,5.34(4.81)$ & \\
Range of disease duration in years, mean (SD) & $36(45)$ \\
Type of vitiligo, $n(\%)$ & $32(40)$ \\
Localised & $12(15)$ \\
Generalised & $10-90,42.3(26.7)$ \\
Acrofacial & \\
Range of VASI score, mean (SD) & $16(20)$ \\
VIDA score, $n(\%)$ & $12(15)$ \\
0 & $32(40)$ \\
+1 & NA \\
+2 & $16(20)$ \\
+3 & $4(5)$ & NA \\
\hline
\end{tabular}

NA: not applicable. SD: standard deviation.

helper type 3 cells; $\mathrm{CD}^{+} \mathrm{T}$ suppressor cells; natural killer $\mathrm{T}$ cells; $\mathrm{CD} 4^{-} \mathrm{CD}^{-} \mathrm{T}$ cells; and $\gamma \delta$ T cells [10].

An altered generation of Tregs or a decrease in their suppressive functions may tip the balance towards autoimmunity, triggering the destruction of melanocytes and development of vitiligo [11].

This study aimed to evaluate the alterations in the numbers of peripheral $\mathrm{CD}^{+} \mathrm{CD}_{2} 5^{+}$and $\mathrm{FoxP}^{+}$Treg lymphocytes by flow cytometry in a sample of Egyptian patients with nonsegmental vitiligo versus health controls and to correlate these alterations with clinical findings of cases including vitiligo disease severity and activity.

\section{Materials and Methods}

2.1. Study Groups. The present case-control study enrolled 80 Egyptian patients with nonsegmental vitiligo, including 36 males (45\%) and 44 females (55\%), in addition to 60 age- and sex-matched healthy volunteers as control subjects, including 36 males (60\%) and 24 females (40\%). Table 1 shows the included subjects' demographic and clinical features. Vitiligo Area Scoring Index (VASI) [12] and Vitiligo Index of Disease Activity (VIDA) score [13] were determined for vitiligo patients. Patients who received systemic steroids or phototherapy for vitiligo in the preceding 6 weeks were excluded. Patients with comorbidities of other dermatologic or systemic diseases that may affect Tregs were also excluded. Two $\mathrm{mL}$ of peripheral venous blood was collected from all included subjects during their visits to the outpatient clinics of Dermatology and Venereology Department of Tanta University Hospitals after signing an informed written consent. Research approval was obtained from the Institutional Ethical Committee of Tanta University.
2.2. Antibodies Used and Flow Cytometric Analysis. The following monoclonal antibodies to human cell-surface molecules were used: anti-CD4-PerCP, anti-CD25-PE, and anti-FoxP3-APC, while the negative controls used were goat IgG-PerCP, IgG-PE, and IgG-APC (Becton-Dickinson Immunocytometry Systems, San Jose, CA, USA). Fluorocytometry was performed with a flow cytometer (FACSCalibur; Becton-Dickinson Immunocytometry Systems) equipped with a $488 \mathrm{~nm}$ blue laser $(488-\mathrm{nm})$ and a red diode laser $(635 \mathrm{~nm})$ for multicolour fluorescence, plus forward-scatter and side-scatter measurements. Automated CellQuest Pro software (Becton-Dickinson Immunocytometry Systems) was used for fluorocytometric data analysis and graphic display, and the instrument was set by using calibrated beads provided. A minimum of 10.000 cells was measured in each analysis.

2.3. Statistical Analysis. Data were statistically analyzed by using Statistical Package for Social Sciences (SPSS Version 18 ). Data were expressed as the mean \pm standard deviation, unless otherwise specified. Flow cytometric data were compared statistically among the groups by using the MannWhitney $U$ test. The correlation coefficient $(r)$ was generated by using Spearman's rank correlation. A $P$ value of less than 0.05 was considered a statistically significant difference.

\section{Results}

3.1. Numbers of Peripheral $C D 4^{+} C D 25^{+} T$ Cells in Study Participants. Treg cells were identified within peripheral $\mathrm{CD} 4^{+}$T-cell population according to their expression level of CD25 (Figures 1(a) and 1(b)). CD $4^{+} \mathrm{CD} 25^{+} \mathrm{T}$ cells were $\mathrm{CD} 4{ }^{+} \mathrm{T}$-cell subsets with bright $\mathrm{CD} 25$ surface expression and 


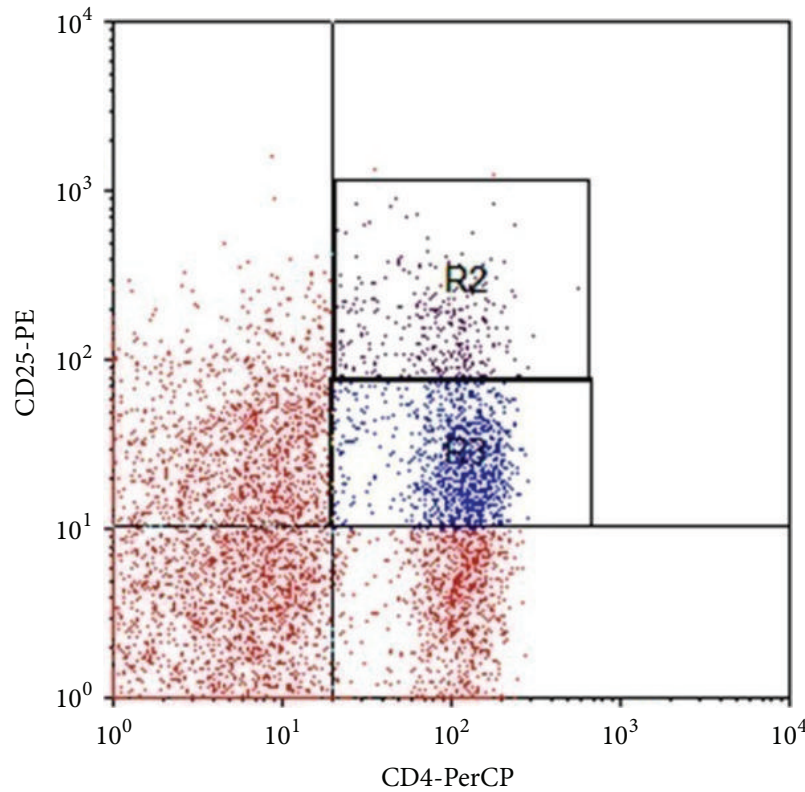

(a)

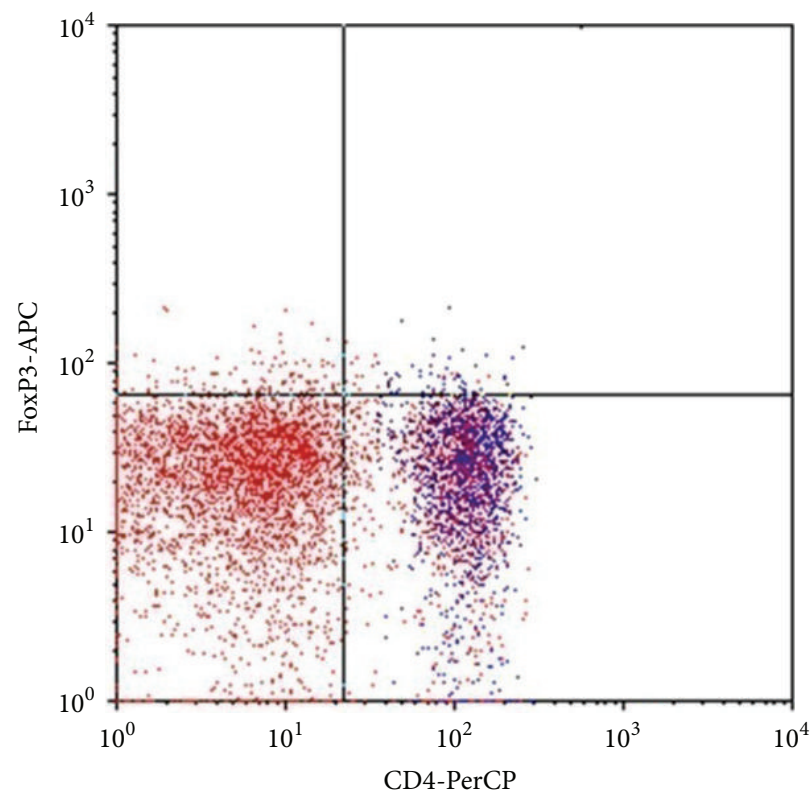

(c)

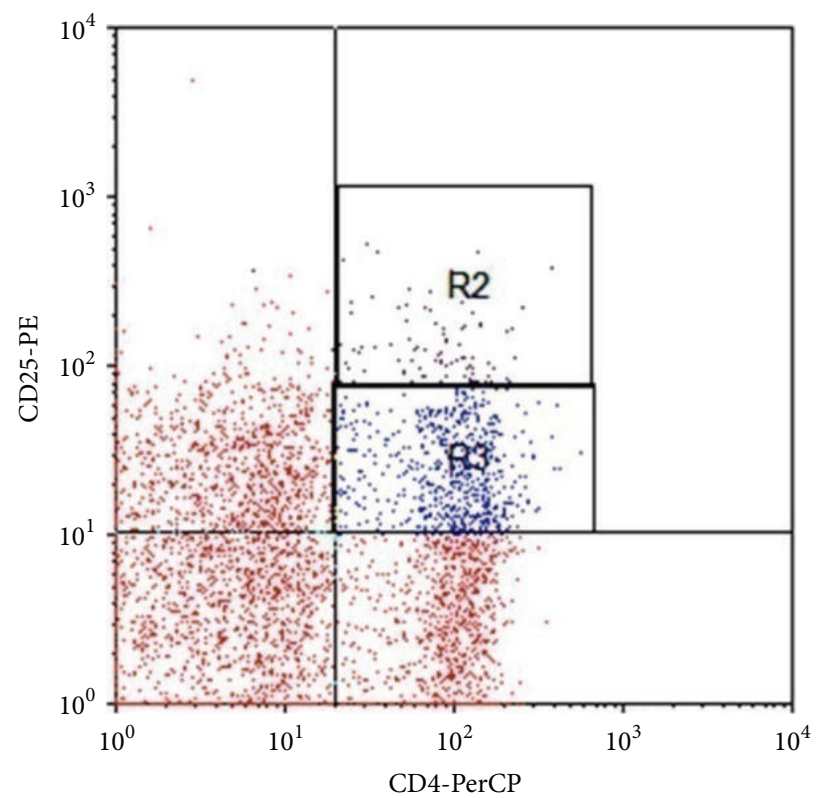

(b)

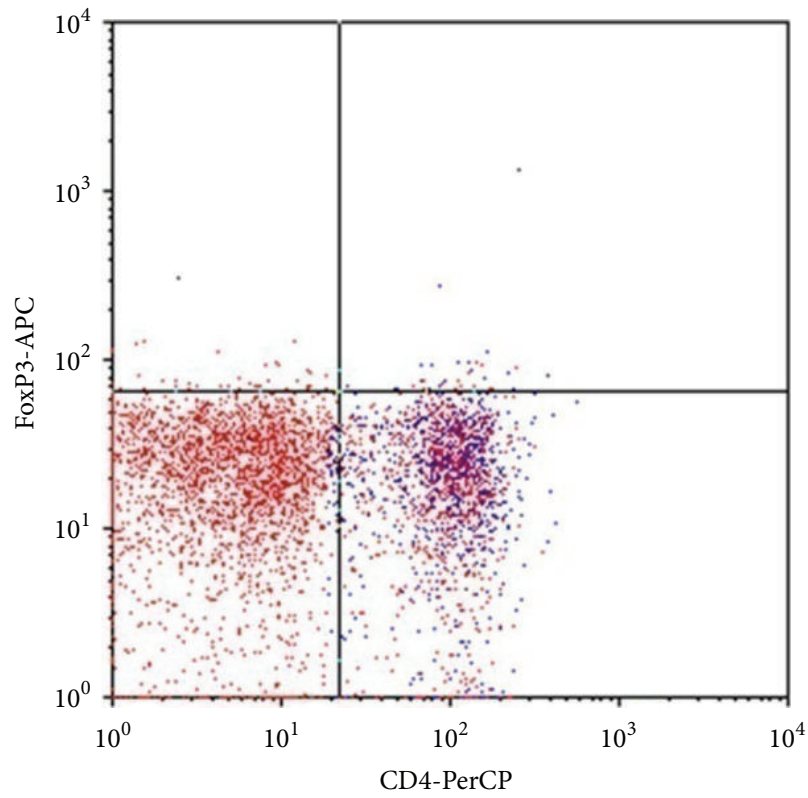

(d)

FIgURE 1: Frequency of circulating $\mathrm{CD} 4{ }^{+} \mathrm{CD} 25^{+}$Tregs and $\mathrm{CD} 4{ }^{+} \mathrm{FoxP} 3^{+} \mathrm{T}$ cells in healthy subjects and nonsegmental vitiligo patients by flow cytometry dot plot. (a) and (b) Representative profiles demonstrating Tregs as the CD $4^{+} \mathrm{CD} 25^{\text {high }}$ (R2) and CD $4^{+} \mathrm{CD} 25^{\text {low }}$ (R3) T-cell fraction by FACS analysis ((a) in a healthy subject, (b) in a vitiligo patient). (c) and (d) Representative profiles demonstrating Tregs as FoxP3 ${ }^{+} \mathrm{CD} 4 \mathrm{~T}$ cells ((c) in a healthy subject, (d) in a vitiligo patient).

were defined accordingly (including both $\mathrm{CD} 44^{+} \mathrm{CD} 25^{\text {low }}$ and, more importantly, $\mathrm{CD} 4^{+} \mathrm{CD} 25^{\text {high }}$ ).

Our results showed a statistically significant decrease in the percentage of peripheral $\mathrm{CD} 4^{+} \mathrm{CD} 25^{+} \mathrm{T}$ cells in vitiligo patients (range from $2.9 \%$ to $34 \%$ of $\mathrm{CD}^{+}{ }^{+} \mathrm{T}$ cells with a mean of $11.49 \% \pm 8.58 \%$ ) compared to healthy controls (range from $17 \%$ to $27 \%$ with a mean of $21.20 \% \pm 3.08 \%$ ) with $P$ value $<0.05$ (Figure 2(a)).
3.2. Numbers of Peripheral FoxP3 $3^{+}$Tregs in Study Participants. FoxP3 expression was determined among the peripheral $\mathrm{CD}^{+} \mathrm{T}$ cells (Figures $1(\mathrm{c})$ and $1(\mathrm{~d})$ ). The percentage of peripheral $\mathrm{FoxP}^{+}$Tregs in vitiligo patients group ranged from $0.6 \%$ to $2.1 \%$ of $\mathrm{CD}^{+} \mathrm{T}$ cells with a mean of $1.09 \% \pm 0.96 \%$ which was significantly lower than that of control group which ranged from $0.04 \%$ to $2.0 \%$ with a mean of $1.44 \% \pm 0.24 \%(P<0.05)$ (Figure $2(\mathrm{~b}))$. 


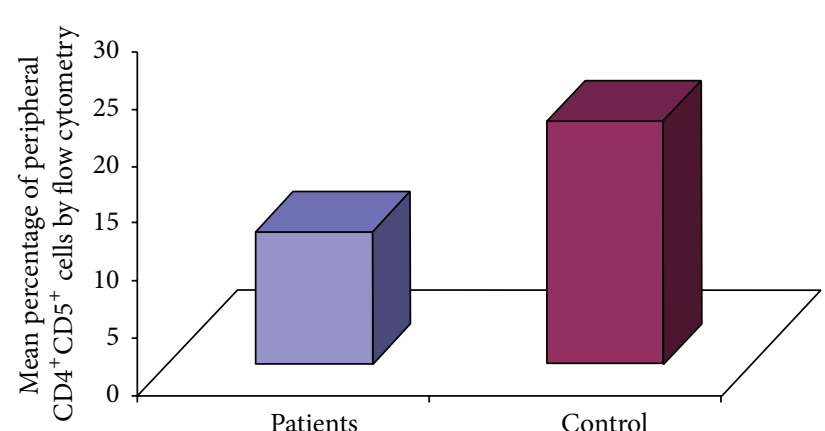

$\square$ Patients

$\square$ Control

(a)

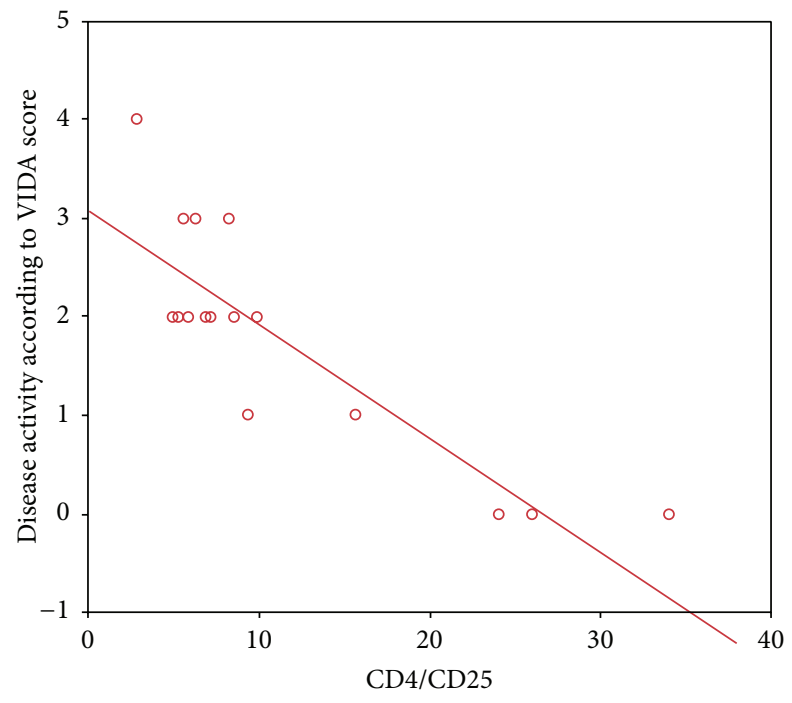

(c)

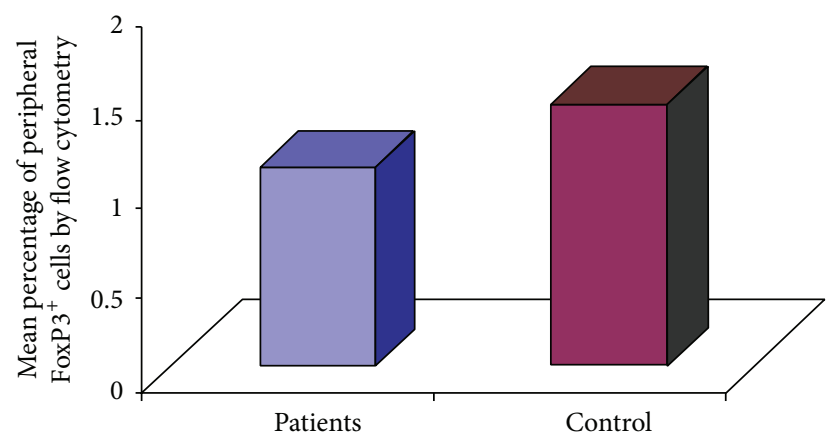

Patients

$\square$ Control

(b)

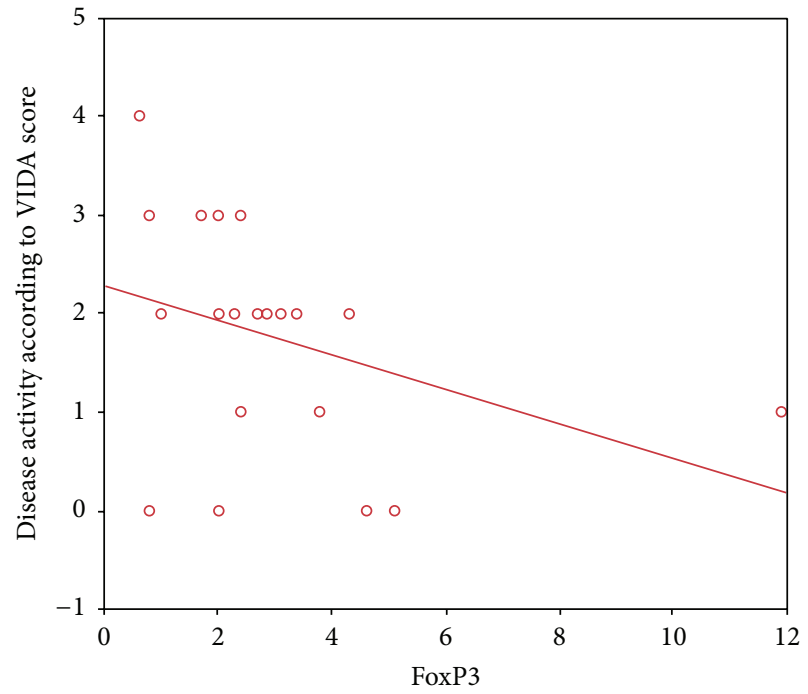

(d)

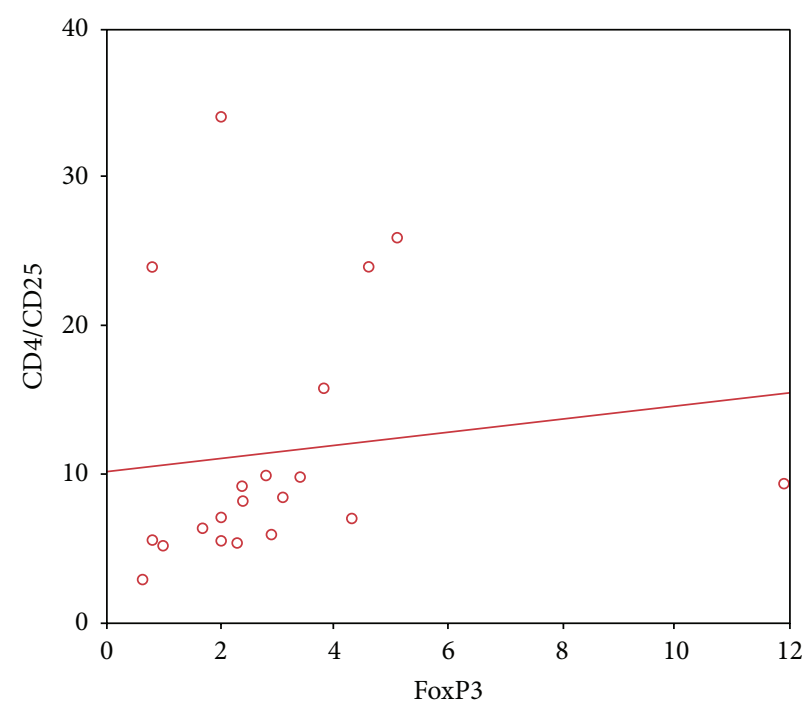

(e)

FIGURE 2: (a) The mean percentage of peripheral $\mathrm{CD} 4^{+} \mathrm{CD} 25^{+}$Treg was significantly reduced in vitiligo compared to healthy controls. (b) The mean percentage of peripheral FoxP $3^{+} \mathrm{T}$ cells from total peripheral $\mathrm{CD} 4^{+}$cells was significantly reduced in vitiligo patients compared to controls. (c) Correlation between percentage of peripheral CD $4^{+} \mathrm{CD} 25^{+}$lymphocytes and VIDA score. (d) Correlation between percentage of peripheral FoxP3 $3^{+}$lymphocytes and VIDA score. (e) Correlation between percentage of peripheral FoxP3 ${ }^{+}$lymphocytes in vitiligo patients group and the percentage of $\mathrm{CD} 4^{+} \mathrm{CD} 25^{+}$lymphocytes in vitiligo patients. 
3.3. Correlation of the Numbers of Peripheral $\mathrm{CD} 4^{+} \mathrm{CD} 25^{+} \mathrm{T}$ Cells and FoxP3 ${ }^{+}$Tregs with the Patients' Clinical Findings and with Each Other. A statistically significant negative correlation was observed between the percentage of $\mathrm{CD} 4^{+} \mathrm{CD} 25^{+}$ $\mathrm{T}$ cells and FoxP3 ${ }^{+}$Tregs in the peripheral blood of vitiligo patients and vitiligo disease activity according to VIDA score $(r=-0.851, P<0.001$ and $r=-0.512, P<0.05$, resp. $)$ (Figures $2(\mathrm{c})$ and $2(\mathrm{~d})$ ), while a statistically significant positive correlation was observed between peripheral percentage of FoxP3 ${ }^{+}$Tregs and the percentage of $\mathrm{CD} 4^{+} \mathrm{CD} 25^{+}$cells in vitiligo patients $(r=0.369, P<0.05)$ (Figure $2(\mathrm{e})$ ).

Each of circulating $\mathrm{CD} 4^{+} \mathrm{CD} 25^{+}$Tregs percentage and $\mathrm{FoxP}^{+}$Tregs percentage did not correlate with patients' age, vitiligo disease duration, or VASI score.

\section{Discussion}

Immunological self-tolerance is maintained not only by deletion of self-reactive lymphocytes in the central lymphoid organs but also by the control of their activation and expansion in the periphery [14]. As a key mechanism of such peripheral self-tolerance, naturally occurring Tregs suppress the expansion/activation of self-reactive $\mathrm{T}$ cells which have escaped thymic negative selection. The majority of these Tregs constitutively express CD25 $5^{+}$(IL-2R $\alpha$-chain) and constitute about $5-10 \%$ of peripheral $\mathrm{CD}^{+}{ }^{+} \mathrm{T}$ cells in mice and humans [15]. Fox $3^{+}$can be specifically expressed in $\mathrm{CD} 4^{+} \mathrm{CD} 25^{+}$Treg cells and it is associated with their development and function [16].

The role of Tregs in vitiligo pathogenesis has been a recent topic of research, and there is evidence that Tregs are jeopardized in vitiligo patients [2]. However, there is some contradicting data and this subject demands further investigation.

In our study, the percentage of $\mathrm{CD} 4^{+} \mathrm{CD} 25^{+} \mathrm{T}$ cells in the peripheral blood of vitiligo patients was significantly lower than healthy controls. This matches the results of several previous reports [17-19].

On the other hand, some other studies had reported a nonsignificant increase in the peripheral percentage of $\mathrm{CD} 4^{+} \mathrm{CD} 25^{+} \mathrm{T}$ cells in vitiligo patients compared to healthy controls $[20,21]$. In another report, the percentage of $\mathrm{CD} 4^{+} \mathrm{CD} 25^{+} \mathrm{T}$ cells was significantly elevated in the vitiligo patient cohort relative to normal control donors and this finding had been considered as a protective mechanism against the autoimmune process. Nevertheless, their observation that peripheral blood levels of these cells apparently did not correlate with severity of the disease or its rate of progression suggested that they may be induced simply by occurrence of the disease and do not correlate directly with autoimmune processes [22].

In the current study a negative correlation was observed between the percentage of peripheral $\mathrm{CD} 4^{+} \mathrm{CD} 25^{+} \mathrm{T}$ cells in vitiligo patients and disease activity according to VIDA score. This result is in agreement with previous studies that detected reduced percentage of $\mathrm{CD} 4^{+} \mathrm{CD} 25^{+} \mathrm{T}$ cells in peripheral blood of progressive vitiligo patients compared to the patients with stable vitiligo, and functional analysis of peripheral Tregs in vitiligo patients showed a correlation of
Tregs functions with the disease status [18, 20]. Moreover, Lili et al. observed that the percentage of circulating Treg cells increased significantly after treatment-induced disease stabilization [19].

In the present study the percentage of peripheral FoxP3 ${ }^{+}$ cells in vitiligo patients was also significantly low compared to healthy controls and this matches previous reports $[18,23]$. On the other hand, Ben Ahmed et al. suggested a recruitment of Tregs from the peripheral blood to the site of vitiligo which was further corroborated by the significant increase of FoxP3 expression in the vitiliginous skin of patients [20].

Among the clinical parameters of our vitiligo patients, a significant negative correlation was detected between the percentage of $\mathrm{FoxP}^{+}$cells in peripheral blood and VIDA score. This comes in agreement with a previous study in which VASI, VIDA, and stress scores correlated negatively with FoxP3 ${ }^{+}$cell levels both in peripheral blood (by real time PCR) and in skin samples (by immunohistochemistry) [23]. However, no evidence of a correlation between Tregs and either activity or duration of vitiligo was found by Moftah et al. in 2014 [24].

In the current study, a significant positive correlation was observed between the peripheral percentage of $\mathrm{FoxP}^{+}$ cells and that of $\mathrm{CD} 4^{+} \mathrm{CD} 25^{+} \mathrm{T}$ cells in vitiligo patients. This matches the results of previous studies [18, 25]. Yagi et al. showed in their study that $\mathrm{FoxP}^{+}$is preferentially and stably expressed in Tregs cells in humans and that ex vivo retroviral gene transfer of $\mathrm{FoxP}^{+}$can convert human naive $\mathrm{CD}^{+} \mathrm{T}$ cells into a regulatory $\mathrm{T}$-cell phenotype similar to $\mathrm{CD} 4^{+} \mathrm{CD} 25^{+}$Tregs cells, indicating that FoxP3 ${ }^{+}$may be a master regulatory gene for the function of $\mathrm{CD} 44^{+} \mathrm{CD} 25^{+}$Treg cells in humans [26].

In vitiligo, the dysfunction of Tregs could result from the alteration of generation, peripheral survival, activation, suppressor mechanisms, or migratory behavior of these cells $[27,28]$. Decreased percentage of peripheral $\mathrm{CD} 4^{+} \mathrm{CD} 25^{+}$ Tregs and decreased expression of $\mathrm{FoxP}^{+}$might impair the suppressive activity of Treg cells on cell proliferation with breakage of tolerance to melanocyte self-antigens which could contribute to the pathogenesis of vitiligo [17]. A previous study had indicated that an imbalance of $\mathrm{CD} 8^{+}$ cytotoxic T lymphocytes and natural Tregs in frequency and function might be involved in the progression of generalized vitiligo. The deficiency and dysfunction of natural Treg cell subpopulations were thought to help in a global expansion and widespread activation of $\mathrm{CD} 8^{+} \mathrm{T}$-cell population, which could result in the destruction of melanocytes and an elevated frequency of associated autoimmune diseases in generalized vitiligo patients [19].

Regulatory cytokines produced by Treg cells, such as IL10 and TGF- $\beta$, are suggested to be related to the stability of vitiligo [29]. In 2013, Tembhre et al. detected increased serum levels of IL-10, IL-13, and IL-17A and decreased concentrations of TGF- $\beta 1$ in patients with vitiligo and that might facilitate the melanocyte cytotoxicity; meanwhile treatment with NB-UVB was capable of elevating TGF- $\beta$ levels, suggesting that Treg cytokines might play an important role in repigmentation [30]. Hegazy et al. proposed that restoration of the balance between Th17 and Tregs might 
represent a novel pathway for the improvement that NBUVB exerts in vitiligo patients [31]. In the same regard, Eby et al. hypothesized that promoting Treg skin homing through enhanced expression of CCL22 might suppress depigmentation in vitiligo [32]. There is a future potential to utilize Treg and Treg-friendly therapies to replace current general immunosuppressives and induce tolerance as a path towards a drug-free strategy without associated toxicities in autoimmune diseases including vitiligo [33].

In conclusion, our results suggest that peripheral Treg depletion with impaired immune downregulatory function might participate in the autoimmune conditions beyond the pathophysiology and activity of nonsegmental vitiligo. Effective Treg cell-based immunotherapies might be a future hope for patients with progressive vitiligo. Larger scale studies might provide a better understanding of Tregs populations and functions, and that might help in successful treatment of autoimmune responses in active vitiligo based on induction or expansion of antigen-specific Tregs.

\section{Conflict of Interests}

The authors declare that there is no conflict of interests regarding the publication of this paper.

\section{References}

[1] A. Alikhan, L. M. Felsten, M. Daly, and V. Petronic-Rosic, "Vitiligo: a comprehensive overview Part I. Introduction, epidemiology, quality of life, diagnosis, differential diagnosis, associations, histopathology, etiology, and work-up," Journal of the American Academy of Dermatology, vol. 65, no. 3, pp. 473491, 2011.

[2] G. F. Mohammed, A. H. Gomaa, and M. S. Al-Dhubaibi, "Highlights in pathogenesis of vitiligo," World Journal of Clinical Cases, vol. 3, no. 3, pp. 221-230, 2015.

[3] K. Ongenae, N. Van Geel, and J.-M. Naeyaert, "Evidence for an autoimmune pathogenesis of vitiligo," Pigment Cell Research, vol. 16, no. 2, pp. 90-100, 2003.

[4] J. Kasznicki and J. Drzewoski, "A case of autoimmune urticaria accompanying autoimmune polyglandular syndrome type III associated with Hashimoto's disease, type 1 diabetes mellitus, and vitiligo," Endokrynologia Polska, vol. 65, no. 4, pp. 320-323, 2014.

[5] N. Oiso, T. Suzuki, K. Fukai, I. Katayama, and A. Kawada, "Nonsegmental vitiligo and autoimmune mechanism," Dermatology Research and Practice, vol. 2011, Article ID 518090, 7 pages, 2011.

[6] Í. Caramalho, H. Nunes-Cabaço, R. B. Foxall, and A. E. Sousa, "Regulatory T-cell development in the human thymus," Frontiers in Immunology, vol. 6, article 395, 2015.

[7] K. E. Birch, M. Vukmanovic-Stejic, J. R. Reed, A. N. Akbar, and M. H. A. Rustin, "The immunomodulatory effects of regulatory T cells: implications for immune regulation in the skin," British Journal of Dermatology, vol. 152, no. 3, pp. 409-417, 2005.

[8] S. Sakaguchi, "Naturally arising $\mathrm{CD} 4^{+}$regulatory $\mathrm{T}$ cells for immunologic self-tolerance and negative control of immune responses," Annual Review of Immunology, vol. 22, pp. 531-562, 2004.

[9] B. Singh, J. A. Schwartz, C. Sandrock, S. M. Bellemore, and E. Nikoopour, "Modulation of autoimmune diseases by interleukin (IL)-17 producing regulatory T helper (Th17) cells,"
Indian Journal of Medical Research, vol. 138, no. 5, pp. 591-594, 2013.

[10] Q. Tang and J. A. Bluestone, “The Foxp3+ regulatory T cell: a jack of all trades, master of regulation," Nature Immunology, vol. 9, no. 3, pp. 239-244, 2008.

[11] R. D'Amelio, C. Frati, A. Fattorossi, and F. Aiuti, "Peripheral T-cell subset imbalance in patients with vitiligo and in their apparently healthy first-degree relatives," Annals of Allergy, vol. 65, no. 2, pp. 143-145, 1990.

[12] I. Hamzavi, H. Jain, D. McLean, J. Shapiro, H. Zeng, and H. Lui, "Parametric modeling of narrowband UV-B phototherapy for vitiligo using a novel quantitative tool: the Vitiligo Area Scoring Index," Archives of Dermatology, vol. 140, no. 6, pp. 677-683, 2004.

[13] T. Kawakami and T. Hashimoto, "Disease severity indexes and treatment evaluation criteria in vitiligo," Dermatology Research and Practice, vol. 2011, Article ID 750342, 3 pages, 2011.

[14] E. M. Shevach, "CD $4{ }^{+} \mathrm{CD} 25^{+}$suppressor T cells: more questions than answers," Nature Reviews Immunology, vol. 2, no. 6, pp. 389-400, 2002.

[15] F. Annunziato, L. Cosmi, F. Liotta et al., "Phenotype, localization, and mechanism of suppression of $\mathrm{CD} 4{ }^{+} \mathrm{CD} 25^{+}$human thymocytes," The Journal of Experimental Medicine, vol. 196, no. 3, pp. 379-387, 2002.

[16] S. Hori, T. Nomura, and S. Sakaguchi, "Control of regulatory T cell development by the transcription factor Foxp3," Science, vol. 299, no. 5609, pp. 1057-1061, 2003.

[17] A. Richetta, S. D’Epiro, M. Salvi et al., "Serum levels of functional T-regs in vitiligo: our experience and mini-review of the literature," European Journal of Dermatology, vol. 23, no. 2, pp. 154-159, 2013.

[18] M. Dwivedi, N. C. Laddha, P. Arora, Y. S. Marfatia, and R. Begum, "Decreased regulatory T-cells and $\mathrm{CD} 4^{+} / \mathrm{CD}^{+}$ratio correlate with disease onset and progression in patients with generalized vitiligo," Pigment Cell \& Melanoma Research, vol. 26, no. 4, pp. 586-591, 2013.

[19] Y. Lili, W. Yi, Y. Ji, S. Yue, S. Weimin, and L. Ming, "Global activation of CD8+ cytotoxic T lymphocytes correlates with an impairment in regulatory $\mathrm{T}$ cells in patients with generalized vitiligo," PLoS ONE, vol. 7, no. 5, Article ID e37513, 2012.

[20] M. Ben Ahmed, I. Zaraa, R. Rekik et al., "Functional defects of peripheral regulatory $\mathrm{T}$ lymphocytes in patients with progressive vitiligo," Pigment Cell and Melanoma Research, vol. 25, no. 1, pp. 99-109, 2012.

[21] J. Klarquist, C. J. Denman, C. Hernandez et al., "Reduced skin homing by functional Treg in vitiligo," Pigment Cell and Melanoma Research, vol. 23, no. 2, pp. 276-286, 2010.

[22] F. Mahmoud, H. Abul, D. Haines, C. Al-Saleh, M. Khajeji, and $\mathrm{K}$. Whaley, "Decreased total numbers of peripheral blood lymphocytes with elevated percentages of CD4+CD45RO+ and CD4+CD25+ of T-helper cells in non-segmental vitiligo," The Journal of Dermatology, vol. 29, no. 2, pp. 68-73, 2002.

[23] M. A. Elela, R. A. Hegazy, M. M. Fawzy, L. A. Rashed, and H. Rasheed, "Interleukin 17, interleukin 22 and FoxP3 expression in tissue and serum of non-segmental vitiligo: a casecontrolled study on eighty-four patients," European Journal of Dermatology, vol. 23, no. 3, pp. 350-355, 2013.

[24] N. H. Moftah, R. A. H. El-Barbary, M. A. Ismail, and N. A. M. Ali, "Effect of narrow band-ultraviolet B on $\mathrm{CD} 4{ }^{+} \mathrm{CD} 25^{\text {high }}$ FoxP ${ }^{+}$T-lymphocytes in the peripheral blood of vitiligo patients," Photodermatology Photoimmunology and Photomedicine, vol. 30, no. 5, pp. 254-261, 2014. 
[25] G. Roncador, P. J. Brown, L. Maestre et al., "Analysis of FOXP3 protein expression in human $\mathrm{CD} 4^{+} \mathrm{CD} 25^{+}$regulatory T cells at the single-cell level," European Journal of Immunology, vol. 35, no. 6, pp. 1681-1691, 2005.

[26] H. Yagi, T. Nomura, K. Nakamura et al., "Crucial role of FOXP3 in the development and function of human $\mathrm{CD} 25^{+} \mathrm{CD} 4^{+}$ regulatory T cells," International Immunology, vol. 16, no. 11, pp. 1643-1656, 2004.

[27] L. J. Chi, H. B. Wang, and W. Z. Wang, "Impairment of circulating $\mathrm{CD}^{+} \mathrm{CD} 25^{+}$regulatory $\mathrm{T}$ cells in patients with chronic inflammatory demyelinating polyradiculoneuropathy," Journal of the Peripheral Nervous System, vol. 13, no. 1, pp. 54-63, 2008.

[28] M. A. Kriegel, T. Lohmann, C. Gabler, N. Blank, J. R. Kalden, and H.-M. Lorenz, "Defective suppressor function of human $\mathrm{CD} 4^{+} \mathrm{CD} 25^{+}$regulatory $\mathrm{T}$ cells in autoimmune polyglandular syndrome type II," Journal of Experimental Medicine, vol. 199, no. 9, pp. 1285-1291, 2004.

[29] A. C. Abreu, G. G. Duarte, J. Y. Miranda, D. G. Ramos, C. G. Ramos, and M. G. Ramos, "Immunological parameters associated with vitiligo treatments: a literature review based on clinical studies," Autoimmune Diseases, vol. 2015, Article ID 196537, 5 pages, 2015.

[30] M. K. Tembhre, V. K. Sharma, A. Sharma, P. Chattopadhyay, and S. Gupta, "T helper and regulatory T cell cytokine profile in active, stable and narrow band ultraviolet $\mathrm{B}$ treated generalized vitiligo," Clinica Chimica Acta, vol. 424, pp. 27-32, 2013.

[31] R. A. Hegazy, M. M. Fawzy, H. I. Gawdat, N. Samir, and L. A. Rashed, "T helper 17 and Tregs: a novel proposed mechanism for NB-UVB in vitiligo," Experimental Dermatology, vol. 23, no. 4, pp. 283-286, 2014.

[32] J. M. Eby, H. Kang, S. T. Tully et al., "CCL22 to activate treg migration and suppress depigmentation in vitiligo," Journal of Investigative Dermatology, vol. 135, no. 6, pp. 1574-1580, 2015.

[33] J. A. Bluestone, E. Trotta, and D. Xu, "The therapeutic potential of regulatory T cells for the treatment of autoimmune disease," Expert Opinion on Therapeutic Targets, vol. 19, no. 8, pp. 10911103, 2015. 


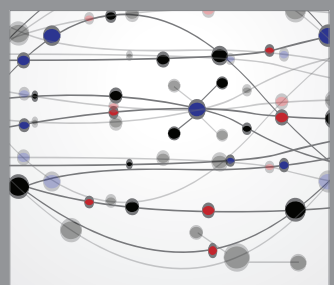

The Scientific World Journal
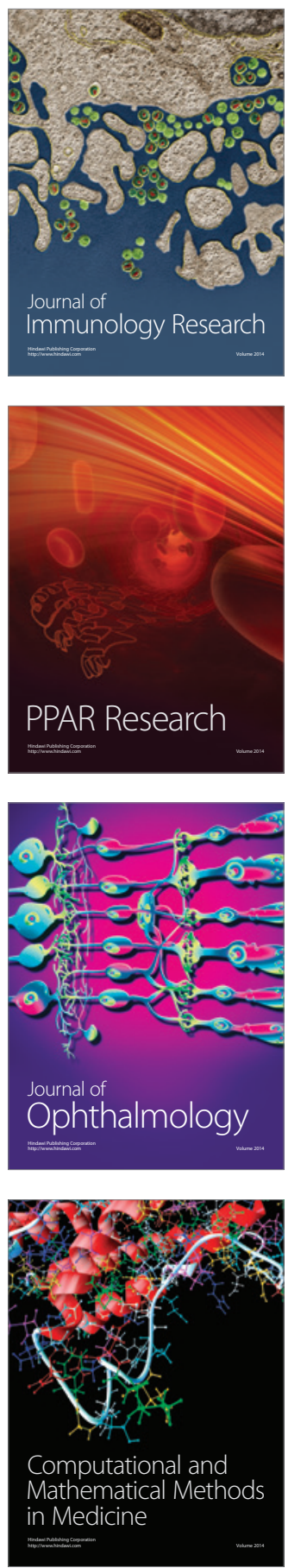

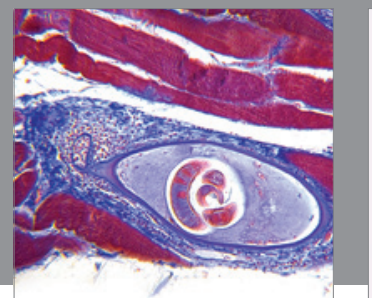

Gastroenterology

Research and Practice
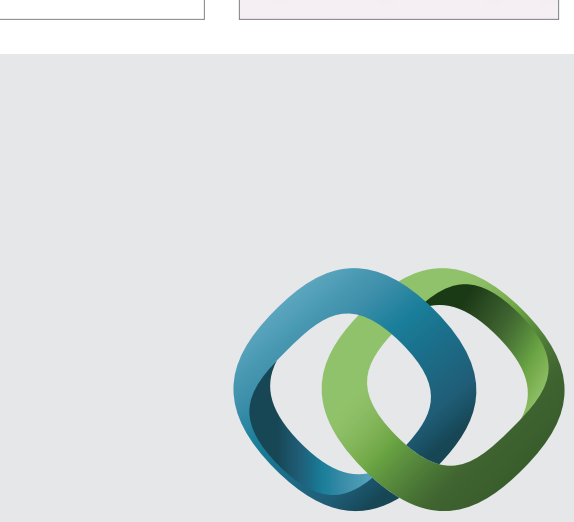

\section{Hindawi}

Submit your manuscripts at

http://www.hindawi.com
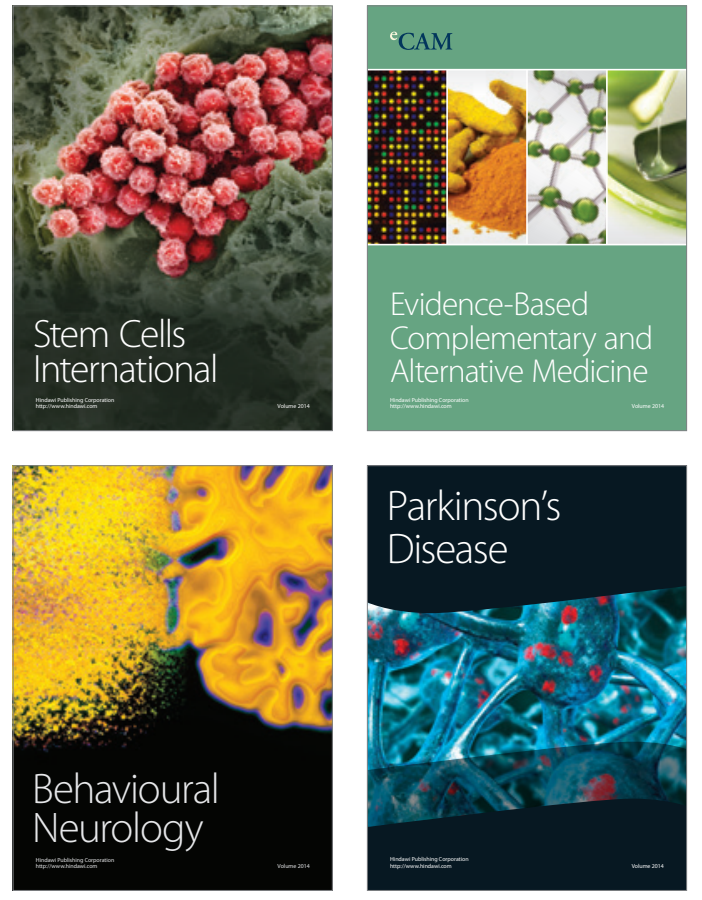
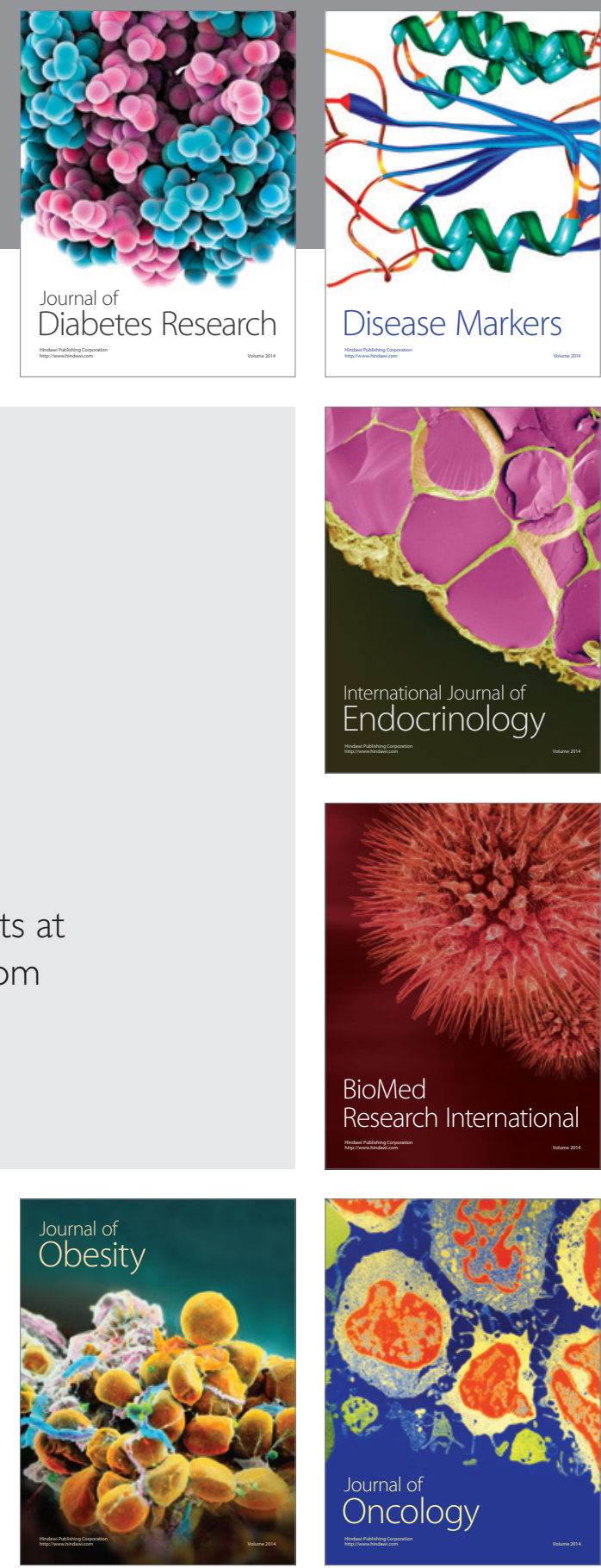

Disease Markers
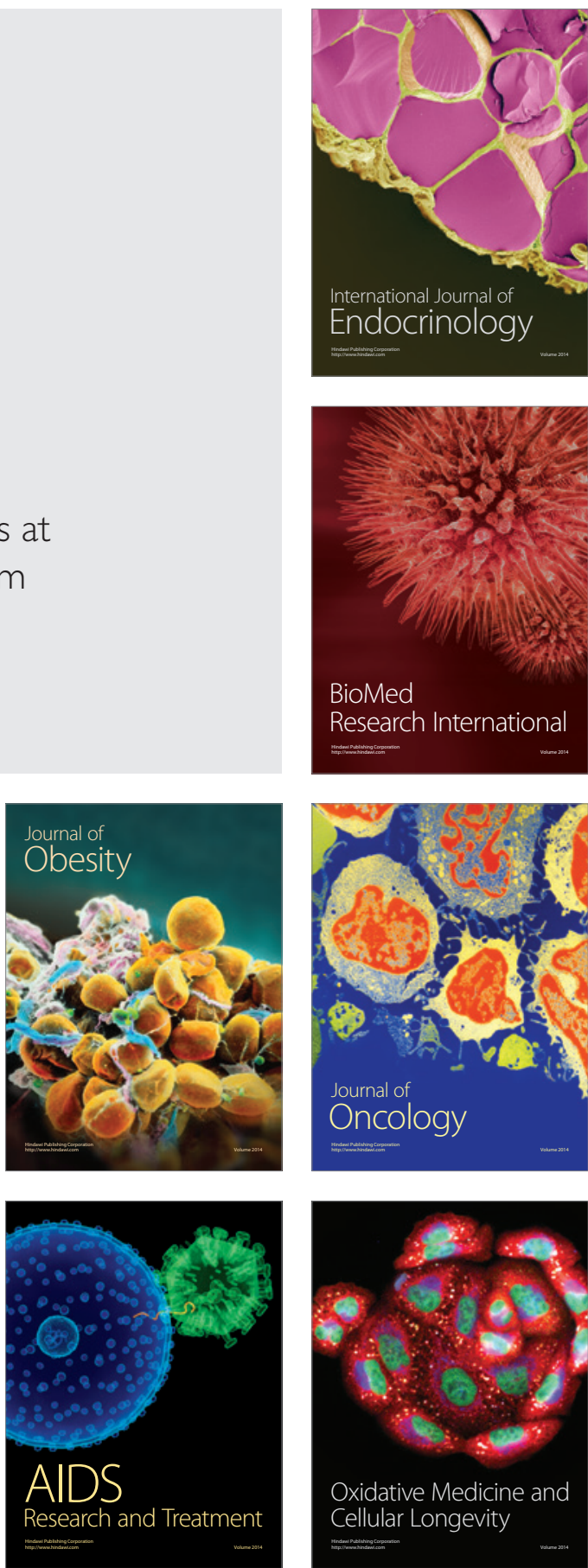